\title{
Analisis Persepsional Siswa Sekolah Dasar pada Konten Video Animasi Dakwah Nabi Ibrahim
}

\author{
Ellys Lestari Pambayun ${ }^{1}$, M Irsyad Agung Nugraha ${ }^{2}$, Muhamad Ibtissam Han ${ }^{3}$ \\ ${ }^{123}$ Institut PTIQ Jakarta, Indonesia \\ 1ellyslestari@ptiq.ac.id \\ ${ }^{2}$ mianugraha14@mhs.ptiq.ac.id \\ 3mibtissamhan@ptiq.ac.id
}

\begin{abstract}
Abstrak
Kajian ini hendak mengeksplorasi persepsi Siswa SD Karawaci Baru VIII Tangerang pada video animasi Kisah Nabi Ibrahim as ini berawal dari semakin memprihantinkannya konenkonten video animasi dan game yang berkonten bahaya atau bisa merusak masa depan generasi bangsa. Video animasi produksi Al-Imran ini memuat dakwah bil hikmah, dakwah bil mau'izah, dan dakwah jidal bil ahsan di dalamnya. Karena itu, peneliti mencoba mengangkatnya melalui teori persepsi dan pendekatan dakwah bil wasilah melalui metode studi kasus dengan observasi lapangan dan wawancara semistruktur. Hasil kajian ini menjelaskan bahwa Siswa SD Karawaci Baru VIII Tangerang ditunjang oleh para orang tua dan guru mereka dalam menonton video animasi Kisah Nabi Ibrahin as menemukan makna hikmah, mau'izah hasanah, dan jidal ahsan untuk dijadikan sebagai sarana untuk membangun payung atau filter reaksi terhadap berbagai informasi dari luar yang tidak baik atau negative. Secara fungsional (personal) dan struktural (lingkungan luar) para siswa ini cenderung untuk menyukai kisah nabi Ibrahim selain karena motif dalam diri mereka juga berbagai kebutuhan yang tidak mereka dapatkan di tempat lain atau keluarga. Selain itu, ada keinginan untuk menyampaikan seruan tentang kebaikan, kebijaksanaan, dan kesalehan Nabi Ibrahim yang pas buat pembelajaran anak-anak SD ini. Dengan tatanan, akidah, syari'ah, moral, dan budaya; video animasi menjadi jendela kecil untuk menyaksikan berbagai sejarah dan riwayat para nabi yang mulia.
\end{abstract}

Kata Kunci : Persepsi, Video, Animasi, Kisah Nabi Ibrahim

\begin{abstract}
This study aims to explore the perceptions of students of SD Karawaci Baru VIII Tangerang on the animated video The story of the Prophet Ibrahim (as) starting from the growing concern about animated video content and games that contain dangerous content or can damage the future of the nation's generation. This animated video produced by Al-Imran contains da'wah bil wisdom, da'wah bil mau'izah, and da'wah jidal bil ahsan in it. Therefore, the researchers tried to raise it through the theory of perception and the da'wah bil wasilah approach through the case study method with field observations and semi-structured interviews. The results of this study explain that the students of SD Karawaci Baru VIII
\end{abstract}


Tangerang are supported by their parents and teachers in watching the animated video The Story of the Prophet Ibrahim as finding the meaning of wisdom, mau'izah hasanah, and jidal ahsan to be used as a means to build an umbrella or reaction filter against various information from outside that is not good or negative. Functionally (personal) and structurally (external environment) these students tend to like the story of the prophet Ibrahim, apart from their inner motives, as well as various needs that they don't get anywhere else or in their family. In addition, there is a desire to convey a call about the goodness, wisdom, and piety of Prophet Ibrahim which is suitable for learning these elementary school children. With order, creed, shari'ah, morals, and culture; animated videos become a small window to watch the various histories and stories of the noble prophets.

Keywords: Perception, Video, Animation, Story of Prophet Ibrahim

\section{Pendahuluan}

Ledakan digital native membuat anak-anak sekarang semakin 'lekat' dengan teknologi. Gadget canggih seakan tak mau lepas dari di tangan, bukan hanya sekedar mencari informasi dan bermain games, tapi karena memang sudah "nyantel" (behavior attachment). ${ }^{1}$ Almalki dan Al-dajani melaporkan pergaulan dengan media sosial dari 267 peserta yang diteliti, 66,29\% seperti dengan video game sebagian besar berada di tahun ke-3 studi $(26,3 \%)$, sedangkan $93,94 \%$ berada di tahun pertama studi. Usia, tahun studi, pendidikan orang tua, pendapatan, hidup sendiri dianggap sebagai faktor paling umum yang secara signifikan terkait dengan perilaku anak-anak bermain video game. Menurut Halim yang dikutip oleh Almalki dan Aldjani menyebutkan seharusnya pemakaian internet disyaratkan minimal usia 13 tahun, tapi karena tidak ada perivikasi yang signifikan atas aturan tersebut, sehingga anak-anak usia di bawah 13 tahun pun dengan mudah memiliki dan meangkases media sosial. Umumnya, hal tersebut didorong oleh tekanan dari lingkungan pergaualnnya (peer group pressure), di mana saat teman-temannya memiliki media sosial ia pun merasa harus memilikinya juga. ${ }^{2}$

Meski tidak bisa dipungkiri bahwa adanya media sosial memiliki beberapa dampak yang positif seperti kemudahan mengakses informasi, materi untuk tugas sekolah, sampai memperluas jaringan pertemanan siswa. Tetapi ada juga dampak negatif yang ditimbulkan

\footnotetext{
${ }^{1}$ I Dewa Putu Eskasasnanda, "Causes and Effects of Online Video Game Playing among Junior-Senior High School Students in Malang East Java," KOMUNITAS: International Journal of Indonesian Society and Culture 9, no. 2 (15 Agustus 2017): 191-202, https://doi.org/10.15294/komunitas.v9i2.9565.

2 Abdulrahman Abdullah Almalki dan Hind Mohammed Aldajani, "Impact Of Playing Video Games On The Social Behavior And Academic Performance Of Medical Student In Taif City" 24, no. 1 (2020): 14.
} 
Analisis Persepsional Siswa Sekolah Dasar pada Konten Video Animasi Dakwah Nabi Ibrahim

oleh media sosial terhadap anak, seperti menjadi pemalas ${ }^{3}$, kurangnya disiplin dalam menjalankan tugasnya, ${ }^{4}$ sampai menunrunnya kemampuan berinteraksi dengan lingkungannya ${ }^{5}$.

Hal-hal di atas tidak bisa dilepaskan dari ketersediaan konten di media sosial yang didominasi oleh konten hiburan yang tidak mendidik. Misalnya banyak sekali bermunculan Youtuber yang menggunakan kata-kata kasar dalam videonya, ataupun konten-konten prank yang tidak jarang menunjukkan amoralitas. ${ }^{6}$ Konten-konten tersebut tidak menutup kemungkinan dapat dijadikan contoh bagi anak-anak dalam berprilaku. Hal ini didukung oleh sebuah penelitian yang dilakukan oleh Moh. Buyung Alfarisi, 25\% anak di salah satu SMP di Surakarta menuliksan 'Youtuber' sebagai cita-cita mereka.'

Dalam beberapa dekade terakhir muncul fenomena gerakan anti konten negatif di media sosial. Para aktivis dakwah ini mencoba mengembangkan konten-konten berupa animasi-animasi yang bersifat edukatif dan memuat pesan-pesan keagamaan. Animasi yang dibuat menggunakan teknologi yang sama dengan yang digunakan dalam film-film kartun di televisi yang relatif memengaruhi cara berpikir dan perilaku anak-anak. ${ }^{8}$ Beberapa akun seperti Yufidtv.com, Al-Iman TV, VOA-Islam.com, Walisanga.or.id, Dakwah.web.id dan beberapa akun lainnya cukup sering bermunculan di beranda media sosial, baik melalui unggahan dalam akun yang bersangkutan secara langsung maupun yang diunggah ulang oleh pengguna lainnya.

Mengutip sebuah argumentasi dari Hurlock, seorang ahli psikologi perkembangan yang popular di Amerika dan Indonesia, yang menjelaskan bahwa edukasi melalui video animasi dapat menyajikan pesan-pesan yang paling menarik bagi anak-anak, karena memberikan nilai-nilai menyenangkan, menggairahkan, mudah dimengerti, dan merangsang

${ }^{3}$ Sulidar Fitri, "DAMPAK POSITIF DAN NEGATIF SOSIAL MEDIA TERHADAP PERUBAHAN SOSIAL ANAK," NATURALISTIC : Jurnal Kajian Penelitian Pendidikan dan Pembelajaran 1, no. 2 (17 April 2017): 118-23, https://doi.org/10.35568/naturalistic.v1i2.5.

4 Nisa Khairuni, "DAMPAK POSITIF DAN NEGATIF SOSIAL MEDIA TERHADAP PENDIDIKAN AKHLAK ANAK (Studi Kasus di SMP Negeri 2 Kelas VIII Banda Aceh)," JURNAL EDUKASI: Jurnal Bimbingan Konseling 2, no. 1 (30 Agustus 2016): 91, https://doi.org/10.22373/je.v2i1.693.

5 Agus Efendi, Puwani Indri Astuti, dan Nuryani Tri Rahayu, "ANALISIS PENGARUH PENGGUNAAN MEDIA BARU TERHADAP POLA INTERAKSI SOSIAL ANAK DI KABUPATEN SUKOHARJO," Jurnal Penelitian Humaniora 18, no. 2 (12 September 2017): 12, https://doi.org/10.23917/humaniora.v18i2.5188.

${ }^{6}$ Eribka Ruthellia David, Mariam Sondakh, dan Stefi Harilama, "CONTENT IN YOUTUBE VLOG INFLUENCE ON STUDENT ATTITUDES ESTABLISHMENT OF COMMUNICATION SCIENCES FACULTY OF SOCIAL AND POLITICAL SCIENCE UNIVERSITY OF SAM RATULANGI,” no. 1 (2017): 18 .

${ }^{7}$ Moh. Buyung Alfarisi, Hubungan Antara Celebrity Worship Youtuber Dengan Perilaku Imitasi Pada Remaja (Surakarta: Fakultas Psikologi Universitas Muhammadiyah Surakarta, 2017), 3.

${ }^{8}$ Fajri Raihan dkk., "Pengaruh Tayangan Kartun di TV Terhadap Kemampuan Bersosialisasi Anak," Communications 2, no. 1 (3 Februari 2020): 51-66, https://doi.org/10.21009/Communications.2.1.4. 
Ellys Lestari Pambayun, M Irsyad Agung Nugraha, Muhamad Ibtissam Han

imajinasi anak - anak. ${ }^{9}$ Peneliti mencoba mengkaji bagaimana preferensi anak-anak, khususnya siswa sekolah SD Karawaci Baru VIII terhadap media dakwah melalui game online video animasi, khususnya video yang bermuatan dakwah seperti Al-Iman TV dalam kisah Nabi Ibrahim, as. sebagai upaya menangkal diri dari pengaruh negatif game yang destruktif dan menjauhkan dari nilai-nilai agama.

Kajian ini menggunakan pendekaan kualitatif dengan metode studi kasus, sebagaimana Pambayun ${ }^{10}$ jelaskan bahwa metode ini dilakukan terhadap suatu 'objek': persepsi siswa SD Karawaci Baru VIII Tangerang pada Video Animasi Dakwah yang diproduksi Al-Iman tentang Nabi Ibrahim as, yang disebut sebagai 'kasus', secara wawancara mendalam dengan menggunakan berbagai macam sumber data secara triangulasi atau sumber data dari guru sekolah dan orang tua murid.

\section{Pembahasan}

Dua objek penelitian ini, pertama adalah video dakwah animasi Kisah Nabi Ibrahin as produksi Al-Iman TV dan kedua adalah sekelompok siswa SD Karawaci Baru VIII Tangerang yang memberi persepsi pada muatan yang ditontonnya untuk menggali penafsiran pada makna melalui simbol animasi: adakah memuat tiga prinsip dakwah dalam Al-Qur'an yaitu bil-hikmah, mauizhah hasanah, dan jidal ahsan telah diterapkan. ${ }^{11}$ Teori yang digunakan untuk menganalisinya melalui pendekatan Media Dakwah dari berbagai ahli, baik dari ahli komunikasi seperti Severin dan Tankard ${ }^{12}$ maupun dilengkap para mufasir seperti dari Wahbah Zuhaili, ${ }^{13}$ Al-Maraghi, ${ }^{14}$ dan sebagainya juga hadis Nabi Muhammad saw.

\footnotetext{
${ }^{9}$ Elizabeth B Hurlock, Developmental Psychology: A Life-Span Approach (New York: McGraw-Hill, 1980), 162.

${ }^{10}$ Ellys Lestari Pambayun, One Stop Qualitative Research Methodology in Communication (Lentera Ilmu Cendekia, 2018), 5-6.

8.

${ }^{11}$ M. Taufik, Tata, Dakwah Era Digital Seri Komunikasi Islam (Jawa Barat: Pustaka al-Ikhlas, 2013),

12 Werner J Severin dan James W Tankard, Communication Theories: Origins, Methods and Uses in the Mass Media, 2014.

${ }^{13}$ Wahbah Zuhaili Zuhaili, "t. th., al-Tafsir, al-Munir fi al-Aqidah Wa al-Syariah wa al-Manhaj," Beirut: Dar al-Fikr al-mu'ashir, t.t.

${ }^{14}$ Ahmad Mustafa Al-maragi, "Tafsir Al-Maragi 30 Juz," Mesir: Mustafa Al-Babi Al-Halabi. Juz 5 (1974).
} 


\section{Bagan 1. Teori Persepsi Media}

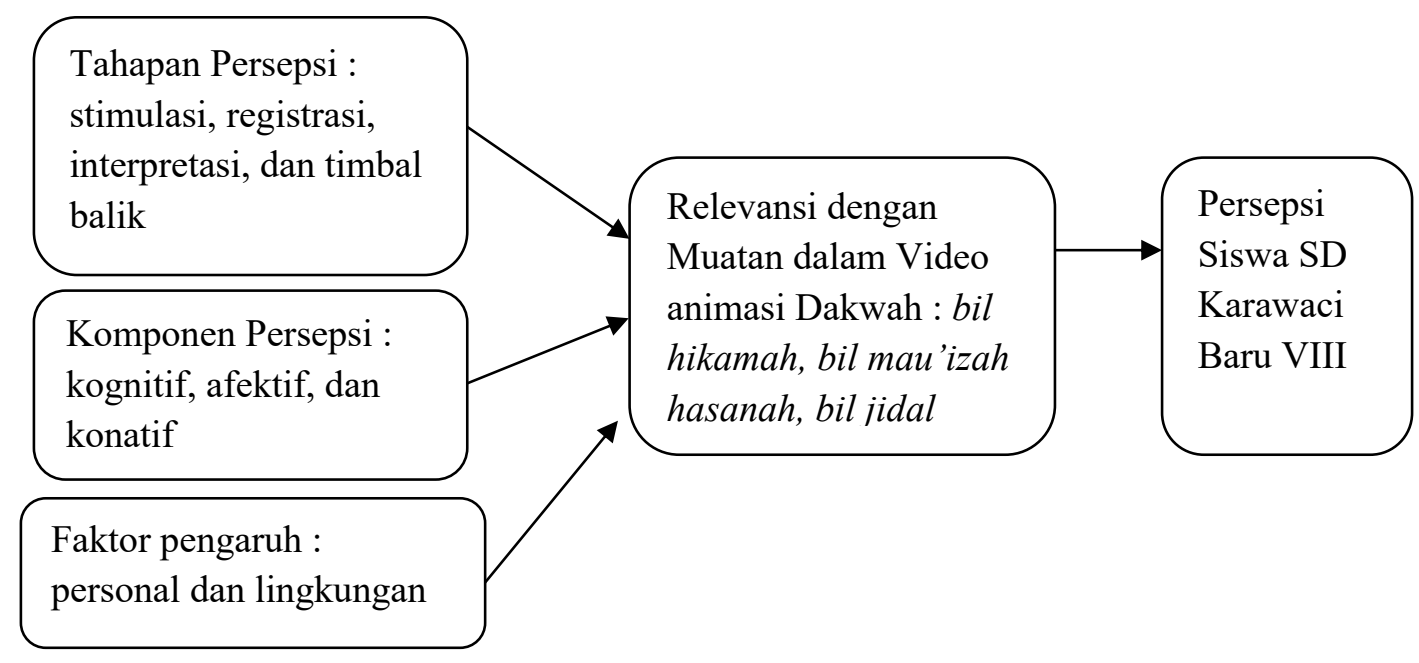

Tahapan Persepsi pada Muatan Dakwah bil Hikmah melalui Video Animasi Kisah Nabi Ibrahim as.

Bennett, Hoffman, dan Prakash dalam Severin dan Tankard menyatakan bahwa "Persepsi merupakan aktivitas aktif yang melibatkan pembelajaran, pembaharuanan, cara pandang, dan pengaruh timbal balik dalam pengamatan". ${ }^{15}$ Artinya, dalam konteks video animasi Kisah Nabi Ibrahin as melaui persepsi siswa SD Karawaci VIII Tangerang sebagai suatu proses mereka dalam memilih, mengorganisasikan dan menafsirkan masukan-masukan informasi dari vide animasi produksi Al-Imran ini untuk menciptakan gambar yang bermakna tentang dunia spiritual mereka. Broadbent menjelaskan bahwa persepsi merupakan proses pengamatan atau pengetahuan mengenai suatu objek atau kejadian tertentu dengan menggunakan alat-alat indera tertentu sebagai perantaranya. ${ }^{16}$

Sedangkan, persepsi yang didasarkan pada pendekatan dakwah bil-hikmah merupakan interpretasi yang datang dari para ahli tafsir. Tiga orang mufasir atau ahli tafsir yang digunakan sebagai rujukan teoretis dalam penelitian ini adalah Quraish Shihab, Mustapha AlMaraghi, dan Wahbah Zuhaili. Menurut tiga mufasir ini, pengertian dari prinsip dakwah bil hikmah adalah menyampaikan ayat Al-Qur'an. Dengan kata lain, sebuah dakwah akan disebut menggunakan prinsip bil-hikmah jika yang disampaikan adalah ayat Al-Qur'an. Karena menurut mereka hikmah adalah Al-Qur'an itu sendiri.

${ }^{15}$ Severin dan Tankard, Communication Theories, 187.

16 D. E Broadbent, Perception and Communication. (Kent: Elsevier Science, 2014), http://qut.eblib.com.au/patron/FullRecord.aspx?p=1875000. 
Di dalam video animasi dakwah ini, ayat Al-Qur'an yang disampaikan diubah menjadi cerita yang disampaikan secara tidak eksplisit dengan membacakan atau menuliskan ayat Al-Qur'an.Yang dilakukan oleh penelitian ini adalah mengamati tahapan proses persepsi, seperti: stimulasi atau situasi yang hadir, proses registrasi, interpretasi/penafsiran, dan umpan balik ${ }^{17}$ yang diberikan siswa SD Karawaci Baru VII, ditunjang pendapat guru SD Karawaci Baru VII, dan orang tua murid (OTM) pada aspek simbolisasi pesan ayat dan simbol non verbal yaitu gambar kartun Kisah Nabi Ibrahim as. Seperti yang diceritakan dalam Surat Al-An'am : 74, yang artinya: “Dan tatkala Ibrahim barkata kepada bapaknya Azar, bagaimanakah kalian mengambil patung itu sebagai tuhan yang disembah. Sungguh diriku melihat kalian dan kaum kalian dalam kesesatan yang nyata”. Melalui gambar Azar yang bekerja membuat patung, gambar patung besar dengan latar belakang patung-patung lain yang dijadikan tuhan sembahan. Juga, diceritakan dalam Surat Al-Anbiya 58, 63, 65 yang digambarkan dalam video animasi disimbolisasi, yaitu: gambar Ibrahim merusak patung, gambar patung besar dengan kalung kapak besar, dan gambar masyarakat yang bingung, apakah benar patung besar berkalung kapak itu yang melakukan. Shihab menjelaskan bahwa adapun ayat 74 s/d 79 dari surat al-An'am berbicara tentang pengalaman Nabi Ibrahim as. bersama orang tua dan kaumnya berkaitan dengan keesaan Allah Swt. Uraian ini dimulai dengan kecaman beliau terhadap orang tua dan kaumnya yang dinilai sesat karena membuat dan menjadikan berhala-berhala sebagai tuhan-tuhan yang disembah (ayat 74). ${ }^{18}$

\section{Stimulus atau Situasi yang Hadir}

Awal mula terjadinya persepsi ketika seseorang dihadapkan pada stimulus atau situasi. Stimulus atau situasi tersebut biasa berupa stimulus penginderaan dekat dan langsung atau berupa lingkungan sosiokultural dan fisik yang menyeluruh dari stimulus tersebut. ${ }^{19}$ Menurut Siswa SD Karawaci Baru VIII, gambar kisah Nabi Ibrahim ini asyik buat ditonton, tidak membosankan. ${ }^{20}$ Karena, gambarnya beragam dan warna-warnanya "aku banget" atau mengikuti selera anak-anak. Guru SD Karawaci Baru VIII juga memberikan hasil stimulasinya, ${ }^{21}$ dengan mengatakan bahwa saat pertama dengar judulnya 'Kisah Nabi Ibrahim

\footnotetext{
${ }^{17}$ Broadbent, Perception and Communication., 89.

18 M. Quraish Shihab, Al-Lubab: Makna, Tujuan, dan Pelajaran dari al-Fatihah dan Juz'Amma (Lentera Hati Group, 2008), 349.

${ }^{19}$ Broadbent, Perception and Communication., 91.

${ }^{20}$ Siswa Kelas VI Sekolah Dasar Karawaci VIII Tangerang, Wawancara Semistruktur, Juni 2018

${ }^{21}$ Guru Sekolah Dasar Karawaci VIII Tangerang, Wawancara Semistruktur, Juli 2018
} 
as' sudah langsung tertarik dan ingin melihat. Apalagi video ini diproduksi youtube anak muslim. Baginya untuk menjadi tuntunan dan tontonan sangat dianjurkan, apa lagi gambarnya bergerak (motion picture) yang lucu dan eye catching buat anak-anak. Orang Tua Murid mengatakan bahwa sebagai orang tua awalnya memang khawatir dengan tontonan anak-anak, meski kisahnya tentang Nabi, karena seringkali kita dibodohi oleh isinya. Ternyata suka diselipkan gambar-gambar yang gak baik buat anak-anak atau gambar kekerasan yang tidak sehat. Tapi, video animasi Kisah Nabi Ibrahim as ini benar-benar memiliki seni yang bagus, dari grafis dan ceritanya. ${ }^{22}$

Gambar 2, Ilustrasi Nabi Ibarahim yang Sedang Dibakar

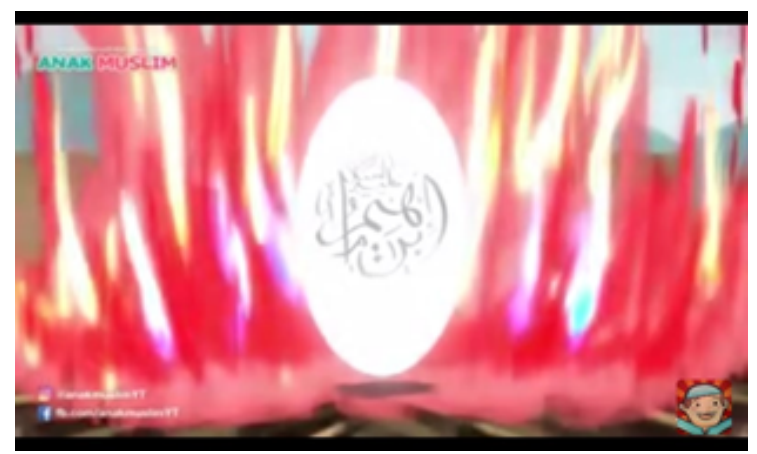

Regristasi

Regristasi di sini merupakan sesuatu gejala yang nampak yaitu mekanisme fisik yang untuk mendengar dan melihat sesuatu informasi maka mualailah orang tersebut mendaftar, mencerna dan menyerap semua informasi. ${ }^{23}$ Menurut siswa SD Karawaci Baru VIII mengatakan awalnya hanya mencoba melihat-lihat dan ikut teman-teman. ${ }^{24}$ Setelah melihat, kemudian men-download sendiri dibantu kakak atau orang tua, lalu menonton sekali lagi agar lebih mengerti yang diceritakan dalam video tersebut. Gambar-gambarnya membuat senang seperti menonton film kartun saja. Guru SD Karawaci Baru VIII mengatakan ${ }^{25}$ sebagai guru senang memotivasi anak-anak didik untuk menonton tayangan yang mengandung hikmah. Apalagi Nabi Ibrahim ini kisahnya ada dalam Al-Qur'an, jadi secara pribadi pun tergugah untuk menonton terus.Orang Tua Murid mengungkapkan video animasi kisah Nabi Ibrahim ini memudahkan untuk menasehati anak-anak, saat kehabisan kata-kata untuk memberi tahu kepada anak-anak. Apalagi anak-anak sekarang susah dikasih tahu, ditambah kurangnya

${ }^{22}$ Orang Tua Murid (OTM) Siswa Kelas VI Sekolah Dasar Karawaci VIII Tangerang, Wawancara Semistruktur, Juli 2018

${ }^{23}$ ROBERT SEKULER, Randolph Blake. Perception (New York: McGraw-Hill, 2006).

${ }^{24}$ Siswa Kelas VI Sekolah Dasar Karawaci VIII Tangerang, Wawancara Semistruktur, Juni 2018

${ }^{25}$ Guru Siswa Kelas VI Sekolah Dasar Karawaci VIII Tangerang, Wawancara Semistruktur, Juli 2018 
waktu bersama dengan mereka, jadi hikmahnya banyak menonton video animasi ini, akan lebih baik. ${ }^{26}$

Gambar 3, Ilustrasi Ayah Nabi Ibrahim yang Sedang Membuat Patung

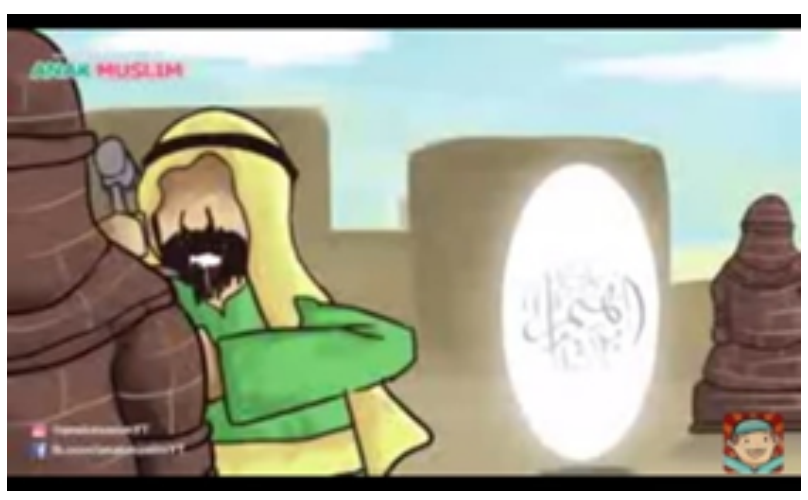

Interpretasi

Tahap selanjutnya setelah informasi tersebut terserap, kemudian proses terakhirnya adalah penafsiran terhadap inforamsi tersebut. ${ }^{27}$ Menurut SD Karawaci Baru VIII menjelaskan bahwa karena video animasi ini jadi agak mau shalat tepat waktu dan tidak banyak main hape. Sehingga, jarang lagi dimarahi ibunya. Karena Nabi Ibrahim mengajari, jika beliau saja tidak memiliki ibu dan ayah kandung, tapi sangat taat dan baik terhadap ayah asuhnya. ${ }^{28}$ Membangkang orang tua sama saja dengan tidak sayang dengan mereka. Guru SD Karawaci Baru VIII, mengatakan tayangan animasi Kisah Nabi Ibrahim ini memberikan kita kesempatan untuk menafsirkan kisahnya secara mendalam. Selain itu, memberikan kita motivasi untuk menghargai orang tua, ketaatan pada pemimpin, dan belajar untuk menghadapi masa sulit. Orang Tua Murid mengatakan ${ }^{29}$ bahwa kisah-kisah nabi itu amat penting untuk menunjang pembelajaran keimanan (tauhid) anak-anak. Tanpa harus ke luar uang atau ke luar rumah bisa menonton bareng tayangan yang bermutu dan mengandung hikmah. Apalagi orang tua yang bekerja seharian jadi bisa menemani anak-anak di rumah sambil saling memperkuat iman masing-masing. ${ }^{30}$

26 Orang Tua Murid (OTM) Siswa Kelas VI Sekolah Dasar Karawaci VIII Tangerang, Wawancara Semistruktur, Juli 2018

${ }^{27}$ SEKULER, Randolph Blake. Perception, 34.

${ }^{28}$ Siswa Kelas VI Sekolah Dasar Karawaci VIII Tangerang, Wawancara Semistruktur, (Juni 2018)

${ }^{29}$ Guru Sekolah Dasar Karawaci VIII Tangerang, Wawancara Semistruktur, (Juli 2018)

30 Orang Tua Murid (OTM) Siswa Kelas VI Sekolah Dasar Karawaci VIII Tangerang, Wawancara Semistruktur, (Juli 2018) 


\section{Umpan Balik}

Merupakan suatu proses yang terakhir, di mana setelah seseorang menafsirkan informasi tersebut, akan muncul reaksi yang positif atau mendukung, cukup positif dan tidak positif atau menolak. ${ }^{31}$ Menurut Siswa SD Karawaci Baru VIII ${ }^{32}$ mengakatan mereka sering bertukar informasi dengan teman-teman kalau ada film animasi yang bagus. Informasi Kisah Nabi Ibrahim as yang ada di youtube Anak Muslim. Sekarang ini masanya sedang cukup sering menonton Nabi Ibrahim. Lalu, kalau lagi main atau ke rumah teman sering saling bertukar cerita lagi. Seru jika bercerita, agar teman-teman tidak bandel lagu dan makin dekat dengan Allah. Proses terbentuknya persepsi menurut DeVitto, timbulnya suatu persepsi dapat terjadi melalui tiga tahapan yang saling terkait, saling memengaruhi, bersifat kontinyu, campur baur dan tumpang tindih antara satu dengan yang lain. ${ }^{33}$

\section{Persepsi Siswa}

Persepsi video animasi Kisah Nabi Ibrahim as pada Siswa SD Karawaci baru VIII melalui muatan dakwah bil hikmah, dakwah bil mauizah hasanah, dan dakwah bil jidal ahsan mendeskripsikan proses fungsional (personal) dan struktural (lingkungan luar).

Persepsi pada Siswa SD Karawaci Baru VIII dalam Tontonan Animasi Kisah Nabi Ibrahim yang Memuat Dakwah bil Hikmah secara fungsional (personal factor) adalah kebutuhan, pengalaman, usia, masa lalu, kepribadian, jenis kelamin, latar belakang pendidikan, demografi ${ }^{34}$ dan lain-lain yang dimiliki Siswa SD Karawaci Baru VIII Tangerang ditunjang guru dan orang tua murid yang bersifat subjektif pada Kisah Nabi Ibrahim melalui video animasi kaitannya dalam melihat dakwah bil hikmah di dalamnya. Analisis dalam konteks ini, bahwa hikmah bisa didapatkan dari pengalaman pribadi, nilai-nilai yang diberikan orang lain kemudian diinternalisasi oleh diri sendiri. ${ }^{35}$ Seperti yang difirmankan Allah dalam surat berikut ini :

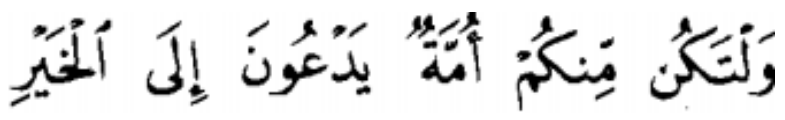

${ }^{31}$ Jalaluddin Rakhmat, “Psikologi Komunikasi, cet,” Ke-26,(Bandung: PT Remaja Rosdakarya), 2008, 54.

32 Siswa Kelas VI Sekolah Dasar Karawaci VIII Tangerang, Wawancara Semistruktur, (Juni 2018)

33 Joseph A Devito, The Interpersonal Communication Book, Global Edition. (Harlow, United Kingdom: Pearson Education Limited,

2018), https://public.ebookcentral.proquest.com/choice/publicfullrecord.aspx? $\mathrm{p}=5573764$.

${ }^{34}$ Rakhmat, "Psikologi Komunikasi, cet," 58.

35 Abdul Kadir Abu dan Didin Hafidhuddin, "Konsep Pendidikan Islam Berbasis Hikmah dalam AlQur'an," Jurnal Ilmiah AL-Jauhari: Jurnal Studi Islam dan Interdisipliner 5, no. 2 (1 Oktober 2020): 147-70, https://doi.org/10.30603/jiaj.v5i2.1803. 
Terjemahan : Dan hendaklah ada diantara kalian segolongan umat menyeru kepada kebaikan (agama) dan seterusnya.... (Q.S. Ali Imran [3]: 104).

Berdasarkan pemaknaan istilah ma'ruf dan munkar yang telah dikemukakan oleh pakar tafsir Al Maraghi dan pakar bahasa Arab di atas dapat dinyatakan bahwa setiap yang bernilai mendatangkan kebaikan bagi diri sendiri dan memberikan kebaikan kepada orang lain, baik dalam bentuk perbuatan maupun sifat yang melekat pada perbuatan atau pada pelaku perbuatan dinamakan ma'ruf. ${ }^{36}$ Sedangkan munkar adalah kebalikan dari ma'ruf, yakni setiap yang bernilai tidak baik bagi diri sendiri dan tidak baik pula bagi orang lain, baik dalam bentuk perbuatan maupun dalam bentuk sifat dan perilaku yang melekat pada pelakunya. Dasar pijakan untuk memberi penilaian apakah sesuatu itu ma'ruf atau munkar adalah pada ketentuan agama (baca Islam), akal sehat dan sesuatu yang sudah menjadi 'uruf (adat) serta norma sosial masyarakat. ${ }^{37}$

Sedangkan secara struktural (lingkungan luar), bisa meliputi lingkungan keluarga, hukum-hukum yang berlaku, dan nilai-nilai dalam masyarakat yang melingkupi kehidupan, seperti yang disampaikan Bandura bahwa lingkungan di luar manusia adalah faktor yang paling signifikan memengaruhi perkembangan sosial. ${ }^{38}$ Siswa SD Karawaci Baru VIII Tangerang berikut guru dan orang tua mereka dalam menonton animasi Kisah Nabi Ibrahim untuk mencari makna dakwah bil hikmah di dalamnya. Jannah mengatakan bahwa hikmah dapat dicari di mana pun, termasuk dalam media sosial seperti video animasi, dengan kisah apapun. ${ }^{39}$ Dalam hal ini khususnya kisah Nabi Ibrahim as. Seperti terdapat pada ayat berikut ini :

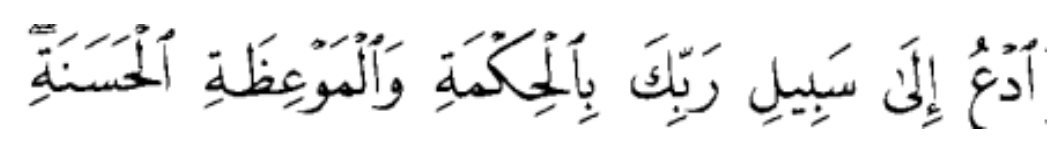

Terjemahan : Dan serulah kepada jalan Tuhanmu, dengan hikmah, pengajaran yang baik, dst...(An-Nahl 125).

Tafsir Kemenag menjelaskan bahwa usai menyebut keteladanan Nabi Ibrahim sebagai imam, nabi, dan rasul, dan meminta Rasulullah saw untuk mengikutinya, pada ayat ini Allah Swt meminta beliau menyerukan kepada manusia menuju ke jalan Allah dengan cara yang baik, "Wahai Nabi Muhammad, seru dan ajaklah manusia kepada jalan yang sesuai tuntunan

\footnotetext{
${ }^{36}$ Al-maragi, "Tafsir Al-Maragi 30 Juz."

${ }^{37}$ Zuhaili, "t. th., al-Tafsir, al-Munir fi al-Aqidah Wa al-Syariah wa al-Manhaj," 32.

${ }^{38}$ Hurlock, Developmental Psychology, 162.

${ }^{39}$ Maisal Jannah, "Keteladanan Tokoh dalam Serial Animasi Nussa Official," Jurnal Peurawi: Media Kajian Komunikasi Islam 3, no. 2 (2020): 1-13.
} 
Tuhanmu yaitu Islam, Allah Swt menjelaskan kepada Rasul-Nya bahwa sesungguhnya dakwah ini adalah dakwah untuk agama Allah sebagai jalan menuju ridha-Nya, bukan dakwah untuk pribadi dai (yang berdakwah) ataupun untuk golongan dan kaumnya. Dakwah tersebut dilakukan dengan hikmah, yakni tegas, benar, serta bijak, dan dengan pengajaran yang baik. Dan berdebatlah dengan mereka, yaitu siapa pun yang menolak, menentang, atau meragukan seruanmu, dengan cara yang baik. Sesungguhnya Tuhanmu yang Maha Memberi petunjuk dan bimbingan. Dialah yang sesungguhnya lebih mengetahui siapa yang sesat serta menyimpang dari jalan-Nya, dan Dialah pula yang lebih mengetahui dari pada kamu siapa yang mendapat petunjuk dan berada di jalan yang benar. ${ }^{40}$

Persepsi Siswa SD Karawaci Baru VIII dalam Tontonan Animasi Kisah Nabi Ibrahim yang Memuat dakwah bil mau'izah hasanah secara fungsional (personal factor), yaitu unsur yang bersifat pribadi, ditentukan oleh karakter, pengalaman, jenis kelamin, demografi, pendidikan, dan sebagainya ${ }^{41}$ yang dimiliki siswa SD Karawaci Baru VIII berukut guru dan orang tua mereka. Sedangkan, unsur struktural (external factor) pengalaman, motivasi, nilai, kebiasaan, dan kemampuan yang didapat dari luar lingkungan ${ }^{42}$ siswa SD karawaci baru VIII berikut guru dan orang tua mereka yang didapat dari animasi Kisah Nabi Ibrahim as melalui dakwah mau'izah hasanah.

Persepsi Siswa SD Karawaci Baru VIII dalam video animasi Kisah Nabi Ibrahim yang memuat dakwah bil jidal ahsan, secara fungsional (personal factor) dapat mengajari bagaimana meredam konflik dan keinginan untuk menyerang orang lain melalui kata-kata. Kisah nabi ini mengajak kita berefleksi untuk melihat persoalan pribadi dengan kacamata kesalehan sang nabi. Secara, struktural (external factor ) unsur ini membahas tentang nilai, hukum, aturan, dan kebiasaan yang didapat dari luar lingkungan, seperti sekolah, tempat bermain, tempat kursus, klub kesenian, majelis taklim, dan sebagainya yang didapat siswa SD Karawaci Baru VIII Tangerang berikut orang tua dan guru mereka melalui animasi Kisah Nabi Ibrahim berkaitan dengan muatan dakwah bil jidal ahsan. Secara struktural, seorang siswa akan melihat persoalan dirinya disebabkan bagaimana ia memeperlakukan orang lain. Selain itu, pengaruh luar akan tidak terlalu berarti bila melihat bagaimana Nabi Ibrahim menyampaikan argumennya dengan logis dan tenang. Analisis dalam konteks ini menjelaskan bahwa terpaan media lebih merupakan kegiatan yang kebetulan dan amat dipengaruhi faktor eksternal. Lingkungan eksternal memainkan peranan yang sangat penting

\footnotetext{
${ }^{40}$ Im Lajnah Kemenar RI, Zaadussalaam Tafsir Ringkas Kemenag, Widya Cahaya, (2020)

${ }^{41}$ Rakhmat, "Psikologi Komunikasi, cet," 78.

${ }^{42}$ Rakhmat, "Psikologi Komunikasi, cet," 79.
} 
dalam menentukan terpaan media, selain faktor internal seperti nilai, norma, aturan, pengalaman, jenis kelamin, pendidikan, pekerjaan, dan demografii ${ }^{43}$ yang dimiliki siswa SD Karawaci Baru VIII dan guru juga orng tua mereka dalam menonton animasi Kisah Nabi Ibrahim yang memiliki makna dakwah bil jidal ahsan. Seperti dalam ayat berikut : Surat An Nahl ayat 125 :

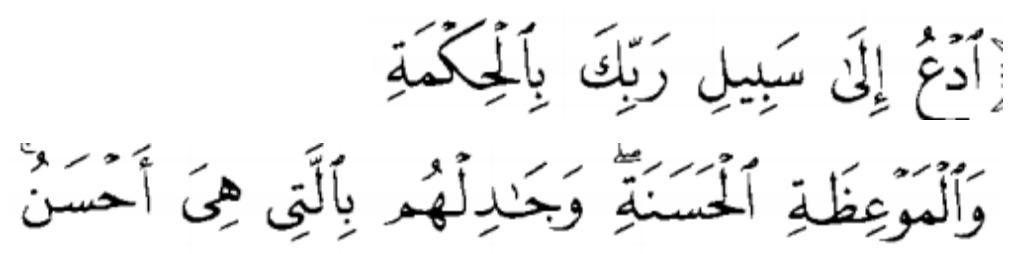

Artinya :Serulah kepada jalan Tuhanmu dengan menggunakan Hikmah, Pengajaran yang baik, dan debatlah dengan cara yang lebih baik dari lawan debat.

Pada ayat Al-Qur'‘an tersebut, kata dakwah disepakati oleh seluruh ulama maupun masyarakat muslim secara umum untuk diartikan sebagai menyeru atau mengajak kepada agama Islam atau dinnul Islam. Dalam hal ini animasi Kisah Ibrahim as ditujukan agar siswa SD Karawaci Baru VIII, guru dan orang tua murid sebagai bagian masyarakat mau untuk beraqidah Islam, bersyariat Islam, dan berakhlak Islam mejauhi perselisihan dan perdebatan yang tidak dianjurkan Allah Swt dan Nabi-Nya. Pendakwah melalui video animasi atau media apa pun sebagai subjek dalam dakwah merupakan orang yang menyeru, mengajak dan mengundang kepada kebaikan. Setidaknya, para pendakwah (da'i) yang menjadi bagian produksi video animasi ini adalah orang-orang yang telah memiliki beberapa kompetensi sebagaimana seorang komunikator harus miliki dalam upaya menggembirakan dakwah, Mubarak dan Halid menyebutkan kopetensi pendakwah, yaitu; good will, good ethos, dan good moral character. Good will adalah sikap dan niat yang kuat dalam menjalankan misi dakwah, good will sangat menentukan sikap da'i dalam melaksanakan aktivitas dakwah. Melalui will yang baik maka da'i akan merasa ringan dalam menghadapi tantangan dan memrpergunakan tantangan sebagai peluang yang akan dicapai secara maksimal. Good ethos adalah kemampuan dalam ilmu dan pengalaman. Melalui good ethos maka ia akan memiliki kecermatan dan kecepatan dalam menghadapi proses dakwah; ia cerdas, terampil, dan berwibawa. Good moral character adalah kepatuhan pada etika dan moral. Da'i

${ }^{43}$ Broadbent, Perception and Communication., 23. 
mensyaratkan dirinya memiliki kebiasaan dan kehidupan yang baik, uswah hasanah dan figur yang mempesona baik fisik, psikis, pengetahuan sosial, maupun spiritual. ${ }^{44}$

\section{Kesimpulan}

Kesukaan video animasi Kisah Nabi Ibrahim as pada Siswa SD Karawaci VIII Tangerang dalam kajian ini lebih merupakan kegiatan yang kebetulan dan prosesnya karena sosialisasi dan interaksi dengan lingkungan teman-teman (eksternal). Lingkungan rumah dan sekolah memainkan peranan yang sangat penting dalam menentukan preferensi seorang siswa pada video animasi. Para siswa ini pun menonton video animasi kisah Nabi Ibrahim as karena siaran televisi tidak memfasilitasi dengan program anak-anak yang mereka sukai dan butuhkan. Walaupun demikian, faktor-faktor personal siswa SD Karawaci VIII Tangerang ini juga sangat menentukan selektivitas dan preferensi pada penggunaan video animasi ini. Seorang siswa SD ini cenderung untuk mempersepsikan konten video animasi dari berbagai masukan (orang tua, teman, dan guru) sebagai motif dan disesuaikan usia dan kebutuhan kognitif dan spiritual mereka. Viseo animasi Kisah nabi Ibrahim as dipersepsikan siswa SD ini selain untuk mencari kesenangan atau hiburan juga pengayaan batin, mencari hikmah atau bermuhasabah. Melarikan diri dari kenyataan. Saar seseorang kesepian, dan berfungsi sebagai sahabat.

Muatan dakwah bil hikmah, dakwah mau'izah hasanah, dakwah bil jidal ahsan berdasarkan pada sayat-ayat Allah Swt melalui para mufasir pada video animasi Kisah Nabi Ibrahim as menemukan penjelasan tentang dakwah yang menggembirakan (tablighul busyro). Karena video animasi ini diproduksi para kreator yang memiliki visi dan misi pada pendidikan anak dan pengembangan akhlakul karimah anak-anak Indonedsia berlandaskan Al-Qur'an, dengan landasan: kompetensi sebagai pendakwah itu sendiri: good will (sikap dan niat yang kuat), good ethos (kemampuan dalam ilmu dan pengalaman), dan good moral character (kepatuhan pada etika dan moral) yang memberikan pemahaman pada anak-anak tetapi tidak kaku dan menakut-nakuti diselingi dengan humor dengan catatan bahwa humor yang disampaikan tidak hanya mengundang tawa tetapi bebas dari unsur-unsur yang melanggar hukum. Rekomendasi pada kajian ini, diharapkan ada kajian lanjutan yang lebih komrehensif dan tajam dalam paradigma dan metodologis tentang perkembangan video animasi yang sangat luar biasa perkembangannya. Pihak otoritas juga hendaknya terus memantau konten video animasi yang mayoritas diproduksi generasi muda dan dikonsumsi yang mayoritas anak-anak-remaja.

\footnotetext{
${ }^{44}$ Muhammad Syahrul Mubarak dan Yusyrifah Halid, "Dakwah yang Menggembirakan Perspektif Alqur'an (Kajian terhadap qs. An-nahl ayat 125)," Al-MUNZIR 13, no. 1 (2020): 35-56.
} 
Ellys Lestari Pambayun, M Irsyad Agung Nugraha, Muhamad Ibtissam Han

\section{Daftar Pustaka}

Abu, Abdul Kadir, dan Didin Hafidhuddin. "Konsep Pendidikan Islam Berbasis Hikmah dalam Al-Qur'an." Jurnal Ilmiah AL-Jauhari: Jurnal Studi Islam dan Interdisipliner 5, no. 2 (1 Oktober 2020): 147-70. https://doi.org/10.30603/jiaj.v5i2.1803.

Alfarisi, Moh. Buyung. Hubungan Antara Celebrity Worship Youtuber Dengan Perilaku Imitasi Pada Remaja. Surakarta: Fakultas Psikologi Universitas Muhammadiyah Surakarta, 2017.

Almalki, Abdulrahman Abdullah, dan Hind Mohammed Aldajani. "Impact Of Playing Video Games On The Social Behavior And Academic Performance Of Medical Student In Taif City" 24, no. 1 (2020): 14.

Al-maragi, Ahmad Mustafa. “Tafsir Al-Maragi 30 Juz.” Mesir: Mustafa Al-Babi Al-Halabi. Juz 5 (1974).

Broadbent, D. E. Perception and Communication. Kent: Elsevier Science, 2014. http://qut.eblib.com.au/patron/FullRecord.aspx?p=1875000.

David, Eribka Ruthellia, Mariam Sondakh, dan Stefi Harilama. "CONTENT IN YOUTUBE VLOG INFLUENCE ON STUDENT ATTITUDES ESTABLISHMENT OF COMMUNICATION SCIENCES FACULTY OF SOCIAL AND POLITICAL SCIENCE UNIVERSITY OF SAM RATULANGI," no. 1 (2017): 18.

Devito, Joseph A. The Interpersonal Communication Book, Global Edition. Harlow, United Kingdom: Pearson $\quad$ Education 2018. https://public.ebookcentral.proquest.com/choice/publicfullrecord.aspx?p=5573764.

Efendi, Agus, Puwani Indri Astuti, dan Nuryani Tri Rahayu. "ANALISIS PENGARUH PENGGUNAAN MEDIA BARU TERHADAP POLA INTERAKSI SOSIAL ANAK DI KABUPATEN SUKOHARJO." Jurnal Penelitian Humaniora 18, no. 2 (12 September 2017): 12. https://doi.org/10.23917/humaniora.v18i2.5188.

Eskasasnanda, I Dewa Putu. "Causes and Effects of Online Video Game Playing among Junior-Senior High School Students in Malang East Java." KOMUNITAS: International Journal of Indonesian Society and Culture 9, no. 2 (15 Agustus 2017): 191-202. https://doi.org/10.15294/komunitas.v9i2.9565.

Fitri, Sulidar. "DAMPAK POSITIF DAN NEGATIF SOSIAL MEDIA TERHADAP PERUBAHAN SOSIAL ANAK." NATURALISTIC: Jurnal Kajian Penelitian Pendidikan dan Pembelajaran 1, no. 2 (17 April 2017): 118-23. https://doi.org/10.35568/naturalistic.v1i2.5.

Hurlock, Elizabeth B. Developmental Psychology: A Life-Span Approach. New York: McGraw-Hill, 1980.

Jannah, Maisal. "Keteladanan Tokoh dalam Serial Animasi Nussa Official." Jurnal Peurawi: Media Kajian Komunikasi Islam 3, no. 2 (2020): 1-13.

Khairuni, Nisa. "DAMPAK POSITIF DAN NEGATIF SOSIAL MEDIA TERHADAP PENDIDIKAN AKHLAK ANAK (Studi Kasus di SMP Negeri 2 Kelas VIII Banda Aceh)." JURNAL EDUKASI: Jurnal Bimbingan Konseling 2, no. 1 (30 Agustus 2016): 91. https://doi.org/10.22373/je.v2i1.693.

Mubarak, Muhammad Syahrul, dan Yusyrifah Halid. "Dakwah yang Menggembirakan Perspektif Al-qur'an (Kajian terhadap qs. An-nahl ayat 125)." Al-MUNZIR 13, no. 1 (2020): 35-56.

Pambayun, Ellys Lestari. One Stop Qualitative Research Methodology in Communication. Lentera Ilmu Cendekia, 2018.

Raihan, Fajri, Fadilla Rachman, Irwan Gita Saputra, dan Muhamad Iqbal Afghan. "Pengaruh Tayangan Kartun di TV Terhadap Kemampuan Bersosialisasi Anak." 
Analisis Persepsional Siswa Sekolah Dasar pada Konten Video Animasi Dakwah Nabi Ibrahim

Communications 2, no. 1 (3 Februari 2020): 51-66. https://doi.org/10.21009/Communications.2.1.4.

Rakhmat, Jalaluddin. "Psikologi Komunikasi, cet." Ke-26,(Bandung: PT Remaja Rosdakarya), 2008.

SEKULER, ROBERT. Randolph Blake. Perception. New York: McGraw-Hill, 2006.

Severin, Werner J, dan James W Tankard. Communication Theories: Origins, Methods and Uses in the Mass Media, 2014.

Shihab, M. Quraish. Al-Lubab: Makna, Tujuan, dan Pelajaran dari al-Fatihah dan Juz'Amma. Lentera Hati Group, 2008.

Taufik, M. Tata, Dakwah Era Digital Seri Komunikasi Islam. Jawa Barat: Pustaka al-Ikhlas, 2013.

Zuhaili, Wahbah Zuhaili. "t. th., al-Tafsir, al-Munir fi al-Aqidah Wa al-Syariah wa alManhaj.” Beirut: Dar al-Fikr al-mu'ashir, t.t. 